\title{
EXPERIÊNCIA E LUXO: POSICIONAMENTO ESTRATÉGICO DO MERCADO DO SEXO NA CIDADE DE GOIÂNIA-GO
}

\author{
Daniel Morais Vieira ${ }^{1}, Y^{\prime}$ carim Melgaço Barbosa ${ }^{2}$ \\ 1 Professor Mestre da Faculdade Cambury (danielvieira235@gmail.com) Goiânia- \\ Brasil \\ 2 Professor Doutor da Pontifícia Universidade Católica de Goiás, Goiânia-Brasil \\ Recebido em: 08/09/2015 - Aprovado em: 14/11/2015 - Publicado em: 01/12/2015 \\ DOI: http://dx.doi.org/10.18677/Enciclopedia_Biosfera_2015_249
}

\begin{abstract}
RESUMO
A prostituição existe desde os primórdios da humanidade. No decorrer do tempo, o sexo camuflado pelo espetáculo encontra nos dias atuais o modelo corporativo. Várias empresas têm desenvolvido seus negócios baseados no entretenimento. Para isso, elas utilizam de estratégias para o incremento mercadológico e segmentação de mercado, apresentando crescimento superior ao de empresas tradicionais. Em Goiânia é possível notar algumas empresas que desenvolveram seus negócios orientados ao entretenimento para agregar valor estratégico, atrair clientes e tornar o consumo de seus serviços uma experiência memorável. O campo de estudo dessa pesquisa foi uma casa de shows em Goiânia, que oferece entretenimento adulto a um público que procura exclusividade e discrição. Buscouse investigar se existe relação entre as estratégias do mundo empresarial e a exploração da prostituição como negócio de luxo. Supõe-se que exista segmentação do sexo de luxo e o posicionamento competitivo de mercado diante da concorrência, desde que fundamentada nas economias do entretenimento, mas também na experiência, fazendo com que a prática da prostituição, como produto de luxo, assuma um caráter mais aceitável entre a sociedade.
\end{abstract}

PALAVRAS-CHAVE: Entretenimento, Posicionamento Competitivo, Segmentação de mercado, Sexo de luxo.

\section{EXPERIENCE AND LUXURY: SEX MARKET POSITIONING STRATEGIC IN GOIANIA-GO CITY}

\begin{abstract}
Prostitution has existed since the dawn of humanity. Over time, the camouflaged sex lust is nowadays the corporate model. Several companies have developed their entertainment-based businesses. For this, they use strategies to increase marketing and market segmentation, an increase higher than that of traditional companies. In Goiânia there are some companies who have developed their entertainment-oriented business to add strategic value, attract customers and make use of their services a memorable experience. The research of this field of study is a show house in Goiania, offering adult entertainment to a public looking for exclusivity and discretion. The aim is to investigate whether there is a relationship between the strategies of the
\end{abstract}


business world and the exploitation of prostitution as luxury business. It is assumed that there is targeting the luxury sex and market competitive positioning against the competition as long as grounded in the entertainment economies but also the experience, making the practice of prostitution as a luxury product, to assume a character more acceptable among society.

KEYWORDS: Entertainment, Competitive Positioning, Market segmentation, Luxury sex.

\section{INTRODUÇÃO}

Quando o assunto é sexo, várias são as tentativas de enquadrá-lo em um modelo, seja social, cultural, político ou econômico para sua significação ser mais aceitável. Essa temática envolve um contexto histórico relacionado à definição do gênero e às práticas que, de alguma forma, desenham o que se apreende por sexualidade, como também suas variantes.

O entendimento da sociedade em relação ao sexo foi afetado por vários fatores, dentre eles, cita-se os culturais e religiosos. A prática da prostituição na cultura ocidental perde uma posição de destaque e importância social por estar relacionada aos deuses do Olimpo e assume um caráter pejorativo e pecaminoso com a forte ascensão do Cristianismo.

A legislação muda e torna cada vez mais rígida e severa à exploração do sexo. Com isso, o setor empresarial, que explora esse universo, se vê na obrigação de se adaptar às forças que interferem no negócio e a desenvolver estratégias para manutenção, mas, sobretudo, sua permanência no mercado. Além disso, o consumo de filmes pornográficos, revistas direcionadas a esse assunto, produtos de sex shops e espetáculos erotizados direcionados ao público adulto requerem cada vez mais inovações e customização.

Geralmente, temas relacionados à prostituição remetem a uma avaliação direcionada à exploração sexual, tráfico de pessoas ou outros assuntos de questão moral. Portanto, percebe-se uma movimentação financeira e econômica considerável nesse ramo, construída historicamente, a exemplo dos bordéis que surgiram em uma estrutura empresarial complexa, mas também suscetível às mesmas forças, as quais interferem a qualquer estrutura organizacional. No Brasil, a indústria voltada para esse tipo de negócio está em constante expansão, pois envolve desde o comércio, com diversas lojas e estabelecimentos que já ultrapassam os $R \$ 11$ milhões, até as próprias fábricas (CUNHA \& RIBEIRO, 2014).

Em se tratando da profissionalização, um estudo da Faculdade de Ciências Humanas da Fundação Mineira de Educação e Cultura (FUMEC), no ano de 2000, revela que o Brasil possuía nessa época um contingente de 1,5 milhão de pessoas que vendiam o corpo como fonte de renda. Destaca-se um dado, pelo menos $8 \%$ do total dessas profissionais do sexo, cerca de 120.000 se enquadravam na categoria luxo. Sua trajetória, em geral, começa em casas de massagem ou em boates privês, onde fazem shows de strip-tease e mantêm contatos com potenciais clientes.

Goiânia é uma cidade com mais de 1.430 milhões de habitantes (IBGE, 2015), possui diversas empresas nas mais variadas áreas de atividades. Não diferente dos grandes centros urbanos, em volume de pessoas morando, trafegando e consumindo os produtos e serviços que a cidade oferece.

Algumas dessas atividades relacionados ao sexo são direcionadas a um público que demanda atendimento diferenciado, exclusividade, sigilo, por isso elas utilizam mecanismos da indústria do entretenimento, como forma de atrair os 
clientes. Tem-se, como exemplo, a grande quantidade de outdoors na cidade de Goiânia, divulgando shows de modelos e atrizes do segmento adulto. Esse ramo de atividade movimenta uma fatia considerável do mercado goiano, entretanto esse tema carece de pesquisas econômicas, mercadológicas, mas também de material que caracterize os processos que compõem a cadeia produtiva e os atores envolvidos no negócio.

Nesta perspectiva, objetivou-se identificar estratégias que tornem a oferta do sexo um negócio direcionado a um mercado de luxo e a um público exclusivo, considerando o fato de que se trata de uma atividade que pode, de certa forma, fomentar a exploração sexual. Buscou-se também averiguar as estratégias relacionadas a este mercado, identificando práticas da economia do entretenimento utilizadas por uma casa noturna em Goiânia, bem como demonstrar o entendimento dos atores envolvidos nesse segmento, quanto à economia da experiência.

\section{MATERIAL E MÉTODOS}

Analisou-se o contexto empresarial no universo do sexo de luxo, a partir de uma casa de espetáculos em Goiânia que, por mais de 23 anos, tem adotado estratégias para atrair o público masculino adulto. O estabelecimento oferece aos clientes uma diversidade de shows com modelos e atrizes de destaque nacional, ambiente requintado e sigiloso, tornando o sexo um negócio de luxo, visando à obtenção de vantagem competitiva no mercado goianiense.

O procedimento metodológico consistiu inicialmente de uma pesquisa bibliográfica sobre assuntos relacionados ao objeto de estudo. Na prática, a forma encontrada para a obtenção dos dados necessários foi o uso de fontes secundárias (textos publicados em revistas e jornais, trabalhos acadêmicos, dissertações, etc.) e de entrevistas formais ou informais. A opção por esse método foi devido à abrangência do tema, mas também pela dificuldade de encontrar pessoas dispostas a prestar informações sobre o assunto tratado. Entretanto, após inúmeras tentativas sem sucesso, foi possível entrevistar as profissionais que trabalham na empresa campo da pesquisa.

Assuntos relacionados ao mercado do sexo, tanto no âmbito econômico quanto organizacional, referem-se à estruturação de um negócio, ao mercado da diversão e entretenimento e ao sexo como elemento das necessidades básicas humanas e constituem-se de relevante interesse a serem caracterizados. .

\section{RESULTADOS E DISCUSSÃO}

\section{HISTÓRICO DA PROSTITUIÇÃO}

A prostituição é considerada a profissão mais antiga do mundo, segundo hipótese difundida entre alguns estudiosos e o público em geral (WEITZER, 2010), mas não identificada como algo que permaneceu genérico e igual desde o seu "surgimento" (SWAIN, 2004). A identidade e o comportamento sexual de uma sociedade sofrem alterações em momentos e épocas específicas, e suas representações artísticas têm o papel de mostrar o ideário de um grupo, propiciando a excitação, o prazer ou outra válvula de escape, não exclusivamente masculina.

A cultura ocidental enfatiza e orienta a prática da monogamia, valorizando a procriação e a perpetuação de um modelo familiar tomado como padrão de vida moral. Em contrapartida, a prostituição surge como uma prática que a maioria prefere ignorar, por se tratar de algo fora do padrão estabelecido socialmente. No 
entanto, é notório que houve algumas alterações em função da religião e da economia, abalando esse padrão sexual estabelecido como símbolo de pureza e até mesmo prestígio social.

Conforme STEARNS (2010), a sexualidade humana está flexível em face às novas conjunturas e às questões acerca da sexualidade; seu entendimento e sua prática também estão suscetíveis a essas mudanças. Assim sendo, a apropriação do sexo como moeda de troca, pelo fator de condição ou sobrevivência, acompanha a história da prostituição ao longo de sua existência, desde as sociedades antigas, influindo nos aspectos sociais, econômicos e culturais.

STEARNS (2010) ressalta que:

\begin{abstract}
"As representações artísticas de Príapo eram comuns, mesmo nas casas mais simples, e um conjunto de poemas escritos sob seu nome tratava de temas extremamente obscenos e ligados à luxúria feminina. Obviamente, as casas da elite romana exibiam representações mais contidas do que as casas de famílias de extrato social mais baixo".
\end{abstract}

De acordo com a concepção oriunda da sociedade agrícola sobre comportamento sexual, os casamentos eram essenciais, pois promoviam o aumento da população local. Consequentemente, a possibilidade do aumento da mão de obra para plantio e produção tornou-se um importante aspecto das relações sexuais: a fertilidade dos casais em detrimento do prazer particular. Porém, esse ajuntamento de pessoas gerou outra característica do comportamento sexual fora do conceito da procriação, a prostituição. Ao mesmo tempo, esse modelo de sociedade também demonstrou que "[...] padrões básicos podiam ser expressos por meio de um punhado de maneiras específicas, não apenas em representações artísticas, mas também em comportamentos afetivos" (STEARNS, 2010).

$\mathrm{Na}$ perspectiva cultural, a sociedade greco-romana exerceu grande influência no pensamento acerca do comportamento sexual do ocidente. Os símbolos da sexualidade representados pelos deuses e deusas ressaltavam a importância da beleza (forma física), do erotismo e da pornografia. Com relação à fertilidade, a deusa Vênus conferiu à figura feminina status social devido à capacidade de gerar vida.

Em se tratando do sexo como fonte de prazer ou outras formas de representação, a prostituição aparece com maior destaque, porque, em sua prática, as mulheres têm maior aceitação, justamente pelo fato dessa atividade ligar-se às divindades da cultura grega. Na visão de STEARNS (2010), as prostitutas talvez fossem as únicas mulheres independentes da dominação masculina, controlando sua própria sexualidade, e isso lhes concedia um prestígio elevado, em alguns casos, "sacro".

De deusas à escória da humanidade, as prostitutas já foram respeitadas em sua ocupação. Com o surgimento da sociedade patriarcal, porém, a independência sexual e econômica das mulheres restringiu-se e as meretrizes passaram a ser malvistas. Observa-se que o cristianismo promoveu uma importante mudança no pensamento sobre sexualidade, gerando uma dualidade em sua interpretação: o prazer e a procriação. 
"O cristianismo limitou severamente as representações públicas do sexo, em particular na arte, que se tornou predominantemente orientada por temas religiosos. Nenhuma civilização reduziu tanto como a Europa cristã a expressão da cultura erótica, nem mesmo antes ou durante o próprio período clássico". (STEARNS, 2010).

A sociedade adotara, então, o casamento como um padrão sagrado de comportamento e conduta; o sexo vaginal para fins de procriação como algo aceitável em detrimento do prazer e desejos sexuais libidinosos. Essas limitações e controle do comportamento sexual não conseguiram acabar com os bordéis, que não eram apenas centros de prostituição, mas locais de refúgio para casais adúlteros e refreadores dos apetites sexuais de jovens solteiros.

Considerados locais especializados para a oferta do sexo, entre outros serviços, como instituição pública, os bordéis aparecem em registros na Grécia e também na China. Esses estabelecimentos, com vários outros nomes, como casas de conforto, de massagem, de banho, de lazer, casa da luz vermelha, cabaré, puteiro, entre outros, consistiram em importância social e política. Além disso, ajudavam a conter o apetite sexual do homem. As cidades regulamentavam o seu funcionamento, como também a prática da prostituição, mas não decretavam a sua extinção.

"No geral, o cristianismo, tão importante em outras áreas sexuais, parece ter tido impacto relativamente pequeno sobre esse aspecto da sexualidade urbana, exceto pelo fato de ter tornado singularmente evidente 0 baixo status social dos praticantes e sua privação até mesmo dos direitos básicos de propriedade". (STEARNS, 2010)

Em algumas sociedades, as prostitutas eram capturadas como espólio de guerra, o que as vinculavam à escravidão. $O$ preço em dinheiro, a quantidade negociada numa relação de prostituição, não representava apenas valor monetário. Representava também o valor social da mulher (RUSSO, 2007).

"[...] quanto maior o montante pago para adquirir o serviço por ela oferecido,
mais ela se afasta do estereótipo social ligado à figura da prostituta. A
própria nomenclatura utilizada se modifica: ela deixa de ser prostituta e
passar a ser garota de programa, e tal fato não é indiferente; a força social
de um ou outro termo não pode ser desconsiderada". (RUSSO, 2007)

A emergência das prostitutas como um grupo definido, precisamente porque seus membros atuavam de maneira bastante diversa da esperada, buscando, às vezes, maior independência do controle masculino,foi um dos sintomas emblemáticos das novas complexidades (STEARNS, 2010).

$\mathrm{O}$ padrão de comportamento baseado na tradição e respeito à estrutura familiar cristã e no controle de natalidade, por exemplo, espalhou-se por toda a Europa do século XVIII, novamente apresentando uma dualidade na interpretação quanto ao padrão sexual de comportamento: as classes respeitáveis e as classes não respeitáveis.

Acerca de sua abrangência global, a economia teve um impacto muito maior do que a religião ou o modelo vitoriano nessa mudança relacionada ao sexo. $O$ imperialismo e os deslocamentos econômicos espalharam pelo mundo modelos globais de comportamento que influenciaram de maneira substancial as localidades. 


\begin{abstract}
"A partir de 1870 e século XX adentro, tomou forma uma impressionante campanha global contra a 'escravidão branca'. Diversos grupos reformadores, principalmente líderes feministas, atuaram para mobilizar a opinião pública contra o sequestro de mulheres, que depois eram forçadas a trabalhar na prostituição. Em 1877, 32 mulheres, de sete países ocidentais, fundaram a International Federationof Friends os Young Women (Federação Internacional dos Amigos das Mulheres Jovens)". (STEARNS, 2010).
\end{abstract}

O crescimento das cidades, os homens em maior número, a grande circulação de pessoas consumindo e a satisfação do prazer sexual masculino eram condições irrevogáveis. O sexo estava se globalizando e, desse modo, a inovação, segundo STEARNS (2010), foi a criação de uma opinião mundial tolerante do ponto de vista sexual que podia ser mobilizada contra ações locais. Surgira, portanto, uma nova cultura, mais aberta à discussão e representação da sexualidade.

\begin{abstract}
"O processo de redefinição e ressignificação das práticas e comportamento abertos pela transformação da sexualidade em uma qualidade do eu abriu caminho à diversidade sexual crescente e promoveu o pluralismo, a partir de meados do século 20. Práticas antes consideradas perversão são ressignificadas e relocalizadas, como uma preferência entre outras, enquanto expressões da sexualidade". (RODRIGUES, 2009)
\end{abstract}

O consumismo e a busca pelo prazer sexual deixaram também alguns aspectos negativos, como o turismo e a exploração sexual, além do aumento significativo de doenças sexualmente transmissíveis. Ademais, com o surgimento da Síndrome da Imunodeficiência adquirida (Aids), os serviços relacionados ao sexo viram-se forçados a desenvolver novas práticas em sua oferta.

Em meados do Século XX, o entendimento e a discussão sobre o sexo passaram a ser preocupações mundiais. Em 1958, o Japão aprovou leis antiprostituição; em 1986, o Segundo Congresso Mundial de Prostitutas, realizado em Bruxelas, reivindicou o reconhecimento da profissão como uma ocupação legítima; a Holanda legitimou abertamente a prática da prostituição no ano 2000 , e algumas prostitutas chegaram até mesmo a se sindicalizar; e em 2006, a Declaração dos Direitos das Prostitutas do Sexo na Europa manifestou repúdio contra as novas leis, alegando que estas relegavam a indústria do sexo à clandestinidade e obstruíam as medidas de saúde pública.

No Brasil, as mudanças das políticas públicas direcionadas à prostituição iniciaram a partir da década de 1990, "[...] inaugurando um período de incorporação de novos elementos, perspectivas e sujeitos no debate sobre a prostituição e os direitos das pessoas que exerciam a atividade" (ALVAREZ \& TEIXEIRA RODRIGUES citados por RODRIGUES, 2009). As legislações brasileiras sobre a temática basearam-se na perspectiva de que a prostituição era um "mal necessário", isto é, partiram do entendimento da prostituição como algo útil, porém moralmente reprovada (RODRIGUES, 2009).

Essa perspectiva ficou alheia à prática da prostituição e criminalizou todas as atividades envolvidas com a infraestrutura para o funcionamento de negócios no ramo. Assim se expressa o Código Penal Brasileiro (Redação dada pela Lei 12.015, de 2009): 
Art. 227 - induzir alguém a satisfazer a lascívia de outrem:

Art. 228 - Induzir alguém à prostituição ou outra forma de exploração sexual, facilitá-la, impedir ou dificultar que alguém a abandone.

Art. 229 - Manter, por conta própria ou de terceiro, estabelecimento em que ocorra exploração sexual, haja ou não, intuito de lucro ou mediação direta do proprietário ou gerente. (BRASIL, 2009).

Os aspectos positivos ou negativos relacionados à sexualidade incentivaram a criação de medidas de regulamentação e controle do comportamento sexual, sejam de aspecto moral ou jurídico (RUSSO, 2007). No entanto, a prática do consumo e o pagamento por serviços sexuais confundem até mesmo as prostitutas quanto ao seu enquadramento social.

É importante ressaltar que a globalização reduziu o abismo informacional entre os países e as pessoas e facilitou a comunicação, gerando uma enorme complexidade de tendências e criações no contexto sexual, o que transpõem facilmente as barreiras físicas das fronteiras. No que tange ao comportamento sexual, a curiosidade e a necessidade cada vez maior por novidades têm causado, na sociedade de um modo geral, uma expectativa sempre iminente por inovações e uma considerável dificuldade em prever mudanças futuras.

Nesse contexto, a busca pelo prazer, o grande interesse pelo sexo, de modo geral e o processo de industrialização criaram uma diversidade de inovações em produtos e serviços relacionados ao sexo, tais como: o crescimento do mercado de revistas, como também de filmes com conteúdo erótico e pornográfico, surgimento de lojas de venda de artigos relacionados ao sexo (sex shops), casas de shows especializadas em entretenimento adulto oferecendo espetáculo de strip-tease e sexo ao vivo, programas em canais de televisão envolvendo atores, atrizes, modelos famosos com conteúdos eróticos e uma infinidade de sites pornográficos.

Pelo fato de o entretenimento adulto ter se tornado a estratégia de atuação de várias empresas pelo mundo, como incremento mercadológico ao mercado do sexo e também devido ao desenvolvimento do próprio negócio da prostituição, apresentando crescimento superior ao de empresas tradicionais, até mesmo cidades, como Las Vegas, entre outras, têm-se percebido o grande potencial econômico que há na exploração desse segmento.

\section{ESTRATÉGIA E POSICIONAMENTO}

Considera-se a premissa de que, no universo do mercado do sexo, "o que se troca são os serviços sexuais, que têm um valor de uso baseado na qualidade própria (o sexo/idade/estética) da natureza do lugar deste trabalho" (LEAL, 2010), conceito que caracteriza as atividades do Real Privê (RP) e o mercado-alvo (atratividade) para o qual são ofertadas tais atividades.

O campo de pesquisa, em questão, tratou-se de uma casa noturna de entretenimento adulto, localizada na cidade de Goiânia. Como estratégia metodológica foi necessária a realização de visitas in loco para confirmação das hipóteses levantadas, bem como uma entrevista com o proprietário para referendar as informações levantadas.

O RP já existe no mercado há mais de duas décadas e sua mudança estratégica se inicia com a compra da empresa há 10 anos pelo atual proprietário, que, costumeiramente, o frequentava e já identificava algumas falhas em relação ao atendimento aos clientes. Em uma de suas visitas a casa, fez uma proposta de compra para a antiga proprietária. Com a proposta aceita e contrato fechado, ele 
assume a direção e resolve inserir conceitos e ferramentas de gestão para a administração do negócio, o que the rende notoriedade no mercado de entretenimento adulto.

$\mathrm{Na}$ atualidade, um dos maiores desafios dos gestores reside na tarefa de prever as mudanças e antecipar-se a elas. O planejamento e as estratégias, neste ambiente de dinamismo e incertezas em que vivem as empresas, são pontos fundamentais para reflexão dos gestores. Nesse sentido, inúmeros são os benefícios que podem ser alcançados com o correto uso da administração estratégica: "Uma organização pode obter diversos benefícios praticando apropriadamente a administração estratégica. Talvez o mais importante deles seja a tendência a aumentar seus níveis de lucratividade [...].” (CERTO \& PETER, 2010).

Estratégias são projetadas para que empresas alcancem seus objetivos. Esse processo inclui atividades de seleção e desenvolvimento de estratégias gerais e, posteriormente, tomadas de decisões específicas a respeito do papel das diversas linhas de negócios da organização e da quantidade de recursos a serem alocados.

Avaliando que as atividades comerciais de uma cidade acabam por desenhar e delimitar territórios, pode-se facilmente perceber o alinhamento entre gestão e desenho territorial no tangente à estratégia de negócio $\mathrm{RP}$, que está localizado na BR-153, cercado por vários estabelecimentos que têm como atividade-fim o comércio do sexo, por isso a região é conhecida como região dos motéis.

Esta proximidade do RP com os motéis auxilia na movimentação e comercialização do sexo. "O pessoal gasta menos de cinco minutos até o motel", afirma a recepcionista do local em entrevista informal. Isso diminui o tempo entre um programa e outro realizado pelas profissionais do sexo que trabalham na casa, além de fazer com que permaneçam mais tempo no estabelecimento, pois são elas que atraem os clientes ao local e torna o negócio viável.

Em uma área de $30 \mathrm{mil} \mathrm{m}^{2}$, o RP oferece um amplo estacionamento para seus clientes com segurança, heliponto e uma localização estratégica, o que facilita a chegada de seus clientes, por se localizar às margens de uma rodovia de grande movimentação. Hoje, devido ao desenvolvimento da Região Metropolitana de Goiânia, que redesenhou a distribuição territorial do local em questão, esta localização facilita o acesso a regiões mais nobres da cidade, como Jardim Goiás, Alphaville Flamboyant e Aldeia do Vale.

Evidencia-se na estrutura física e na organização dos bastidores dos shows, que há um cuidado importante com o espetáculo. Há no local um salão com cabeleireiro, maquiador e manicure para cuidar das dançarinas, bem como o esforço do empresário de sempre levar mulheres que são destaques nacionais na mídia para fazerem shows de strip tease para atrair os clientes. Foi possível ver a dinâmica territorial levantada anteriormente em estudos e discussões (nesse caso refere-se à localização estratégica da empresa e de como essa influenciou as atividades das empresas que se instalaram na mesma região).

Pelos aspectos acima mencionados, observa-se que o RP utiliza da oferta de produtos e serviços de luxo para segmentação do negócio, se levar em conta o consumo de luxo como forma de reconhecimento pelo outro é, atualmente, acompanhado do desejo de proporcionar prazer e bem-estar. Mais do que simplesmente se distinguir socialmente, o consumidor de luxo atual quer experiências prazerosas e de cuidado que o façam se sentir especial.

KOTLER \& ARMSTRONG (2010) citam variáveis para a segmentação baseada no comportamento dos compradores, são elas: papéis exercidos na 
tomada de decisão de compra, ocasiões de compra, benefícios procurados, status de usuário, taxa de uso, estágio de disposição para a compra, nível de lealdade e atitudes.

De acordo com DANZIGER (2005), esta é a evolução natural dos conceitos de luxo: do topo para as massas, fenômeno também conhecido como mastigo, de prestígio para as massas. "Quando a maioria dos consumidores pode adquirir os bens que preenchem suas necessidades básicas de sobrevivência e ainda lhes resta algum dinheiro, tendem a adquirir produtos e serviços que possuam significado emocional para eles." (SILVERSTEIN et al., 2005).

Quando se trata de mercado de consumo algumas práticas são referendadas pelo mecanismo de oferta, demanda de produtos e serviços. Dessa forma, a avaliação de mercado trata o produto como objeto, independente do que se oferece ou compra. Porém o que aponta para uma diferenciação é o contexto em que se apresenta a oferta deste produto. Na visão de BAUDRILLARD (1995):

\footnotetext{
"Raros são os objetos que hoje se oferecem isolados, sem o contexto de objetos que os exprimam. Transformou-se a relação do consumidor ao objeto: já não se refere a tal objeto na sua utilidade específica, mas ao conjunto de objetos na sua significação total".
}

Muito do que tem sido escrito sobre estratégia pressupõe sua conceituação como um conjunto de diretrizes conscientemente deliberadas que orientam as decisões organizacionais. Esse conceito, chamado por MINTZBERG (1978) de estratégia intencionada, é representativo das escolas prescritivas de pensamento. De acordo com o autor, "[...] esta abordagem pode ser percebida, por exemplo, em um dos pressupostos da escola de aprendizagem: 'estratégias' aparecem primeiro como padrões percebidos no passado e somente mais tarde, talvez, como planos deliberados para o futuro [...]" (MINTZBERG, 1990).

Nesse sentido, entende-se que o mercado é uma das principais forças que selecionam as empresas que estariam aptas a se manter nesse contexto. Por outro lado, imperfeições do mercado permitem a existência de estratégias não estabelecidas formalmente, que emergem de um padrão de decisões passadas, baseadas em contextos financeiros ou em observações de concorrentes diretos.

Embora a ideia de estratégia, não de maneira formalizada, possa parecer subjetiva para a maioria das empresas, o posicionamento competitivo não depende somente de uma "vontade" empresarial. Depende, também, do movimento do mercado em relação ao produto/serviço de seus concorrentes e substitutos.

HENDERSON (1998) acredita que a competição é anterior ao surgimento da estratégia. Para esse autor, com o surgimento da vida, iniciou-se a competição, e quanto mais rico o ambiente, maior o número de variáveis potencialmente significativas que podem proporcionar a cada espécie uma vantagem única. Contudo, quanto mais rico o ambiente, maior o número de competidores, e, consequentemente, mais acirrada a competição. Para esse autor, o número crescente de competidores numa dimensão infinita, em um planeta finito, faz com que eles acabem eliminando uns aos outros. Os mais aptos sobrevivem e prosperam, até que tenham expulsado seus competidores, ou crescem além do que seus recursos permitam. Competidores que conseguem se sustentar de maneira similar não podem coexistir, seja nos negócios ou na natureza. Desse modo, é necessário que cada um seja suficientemente diferente para que possa conseguir uma vantagem competitiva. 
O posicionamento competitivo de uma empresa é "uma declaração dos mercados-alvo, isto é, onde a empresa irá competir e a vantagem diferencial, ou seja, como a empresa irá competir" (HOOLEY et al., 2011). Reconhece-se, aqui, a importância da empresa em determinar como deseja colocar seu produto/serviço no mercado competitivo e os fatores intangíveis para a construção de relações com os consumidores.

$\mathrm{Na}$ definição de KOTLER (2009), posicionamento de mercado é concebido como "[...] o ato de desenvolver a oferta e a imagem da empresa, de maneira que ocupe uma posição competitiva, distinta e significativa nas mentes dos consumidores-alvos." Assim sendo, é imprescindível que a empresa estude as características dos seus clientes, suas necessidades, gostos e percepções, de modo a criar uma relação mais forte com eles, que os levem à percepção de que o produto oferecido por ela é único.

De acordo com o empresário do RP, todo o empreendimento foi criado para oferecer conforto e sofisticação aos clientes, para fazer com que eles se desliguem de suas rotinas, vivenciem as atividades que a casa proporciona, em termos de entretenimento do sexo de luxo.

Por este aspecto, foi questionado ao proprietário se ele considera sua empresa um negócio de luxo e que exclui determinados possíveis consumidores. "Não considero meu negócio de luxo, não crio um padrão de atendimento único, as mulheres que trabalham aqui não tem um padrão de modelos, tenho aqui mulheres altas, baixas, negras, brancas, mais magras, mais gordinhas, a intenção é satisfazer a todos os gostos.".

O conceito de luxo por vezes é compreendido como algo irrestrito, porém o RP não atua como um clube fechado para pessoas exclusivas. Dessa forma, não há uma distinção do entretenimento como um negócio economicamente viável e visível com outros negócios da economia tradicional e, por isso "[...] o entretenimento não pode ser algo complicado ao consumidor, deve ser algo simples e prazeroso (WOLF, 1999)". Essa ideia reforça a questão da experiência, na qual o cliente busca a satisfação de seus desejos, se esforça para obtê-lo e tem uma surpresa positiva em relação à sua expectativa.

Por se tratar de sonho e de aspirações, o luxo apresenta faces diversas, as quais variam de acordo com fatores culturais e sociais. Cada indivíduo interpreta o luxo à sua maneira, pois este é mais do que produtos e serviços, uma vez que ele vem carregado de significados que o traduzem, o reafirmam e sofreram alterações ao longo do tempo. Reflete uma época ou de uma sociedade. O luxo caracterizado pela ostentação de antigamente é hoje sucedido pelo luxo sutil (CASTARÈDE, 2005).

Em sua concepção tradicional, o significado de luxo remete ao conceito de distinção social, pois foi durante muito tempo manifestação de riqueza e sucesso, um espetáculo de ostentação. Hoje, ele não se resume à luta de classes. Demonstrações de poder e classe social continuam até hoje, mas concedem espaço para experiências de prazer imediato, de cuidado com o bem-estar próprio.

Contempla-se hoje a atração pelo luxo dos sentidos, do prazer e da sensibilidade sentida na intimidade pelo indivíduo e não o luxo exterior, da exibição e da opulência que visa simplesmente demonstrar status. O velho luxo está associado ao produto, enquanto o novo está ligado à experiência, ele vem como forma de satisfação própria, não apenas como distinção social (LIPOVETSKY, 2009). A sociedade moderna vislumbra-o de modo diferente. 
Analisando com mais critério, infere-se que o sexo de luxo pode ser entendido dentro de uma sociedade determinada, em dado momento e lugar, ou seja, depende da cultura, como também da história. A concepção do negócio do RP não está orientada para o prestígio social dos frequentadores, mas pela capacidade financeira que necessitam ter para entrar no estabelecimento, consumir, usufruir da exclusividade no atendimento que esse proporciona a eles.

Relato do proprietário: "Não há no RP um lugar mais exclusivo do que já ofereço aqui, temos alguns camarotes, porém nas áreas comuns, não é possível separá-las, os shows são os mesmos, banheiros, bar, o que acontece é que quando alguém quer algo mais exclusivo e restrito é feito eventos em horários de dias que a casa não está aberta ao público".

O empresário tem a intenção de lucrar com pessoas que estão a procura por sexo com mulheres belas, mas também profissionais, clientes dispostos a pagar qualquer valor para isso. Por este aspecto, recorre-se ao pensamento de TRIGO (2013), que entende a experiência como um fluxo de eventos particulares, conhecidos apenas pelo sujeito que os vivencia, levando em consideração as problemáticas relações com outros eventos, como os acontecimentos do mundo externo ou outros fluxos de eventos similares pertencentes a outras pessoas.

Inserido nessa perspectiva, o próximo tópico aborda a economia do entretenimento e da experiência.

\section{ECONOMIA DO ENTRETENIMENTO E AÇÕES ESTRATÉGICAS}

Neste aspecto, quando se trata de estratégia para oferta de produtos e/ou serviços com características temporais curtas, como é o caso da prostituição de luxo, o espetáculo tem um papel fundamental, pois o que restará ao cliente depois de seu uso será a experiência de ter consumido algo exclusivo, por mais que o acesso seja amplo. Dessa forma, em uma sociedade de luxo, o entretenimento passa a ter um papel fundamental no consumo, uma vez que as necessidades básicas mudam conforme o crescimento econômico, financeiro e cultural dos consumidores.

O objeto, a partir do contexto em que está inserido, é percebido, consumido, e a continuidade do produto no mercado pode estar relacionada ao desejo e à intenção do consumidor, superando as próprias expectativas da concepção do produto. Este, em sua característica inicial de concepção, está ligado à temporalidade de seu consumo e, com isso, conta um serviço adicional de divulgação, merchandising e estratégias de oferta, para que seu consumo gere um faturamento capaz de sustentar a empresa que o oferece.

São notórios a volatilidade e o consumo efêmero. Nesse sentido, LIPOVETSKY (2009) afirma que, "[...] no império do valor de uso, não nos ligamos mais às coisas, muda-se facilmente de casa, de carro, de mobiliário". Isso porque, segundo o autor, a era que sacraliza socialmente as mercadorias é aquela na qual o indivíduo separa-se sem dor de seus objetos.

Atualmente, empresas têm apostado cada vez mais no entretenimento para atrair clientes, segmentar mercado e promover seus produtos/serviços, tornando esse um dos maiores setores da economia nacional nos últimos tempos.

Desse modo, quando o assunto é estratégia para oferta de produtos e/ou serviços com características temporais curtas, o espetáculo tem um papel fundamental, pois o que restará ao cliente depois de seu uso será a experiência de ter consumido algo exclusivo, por mais que o acesso seja amplo. 


\begin{abstract}
"Entretenimento é, em muitas partes do mundo, o setor que mais cresce da economia. Isso é tão verdadeiro para as economias em desenvolvimento, como para as desenvolvidas. Mas de impacto ainda maior é a maneira como conteúdos de entretenimento tornaram-se um importante diferencial em praticamente todos os aspectos do consumo". (WOLF, 1999).
\end{abstract}

No universo do entretenimento, existem vários níveis de sucesso. Segundo TRIGO (2003), o principal é o sucesso econômico, ou seja, aquele produto ou serviço que gera um lucro maior ou menor para todos os envolvidos na sua produção ou distribuição. Dessa forma, quando se paga por um serviço, compra-se uma série de atividades que serão realizadas em seu nome. No caso da experiência, adquire-se uma série de eventos memoráveis que a afetam de uma maneira particular.

$\mathrm{Na}$ opinião do proprietário do $\mathrm{RP}$, os valores de entrada e o preço dos produtos vendidos na casa não são acessíveis aos clientes de todas as classes sociais, sendo necessário certo sacrifício para consumir o que o estabelecimento oferece. Contudo, segundo ele, a infraestrutura preparada para atender sua clientela justifica o preço cobrado pela casa.

Por se tratar de um negócio que envolve (in)diretamente a prostituição de luxo, os preços praticados no RP estão acima da concorrência. Segundo entrevista informal (observador participante) com um garçom do local, o consumo médio por pessoa em uma noite no estabelecimento, referente a bebidas e comidas, gira em torno de $R \$ 500,00$. Isso, sem calcular o valor da entrada de $R \$ 65,00$.

$\mathrm{Na}$ economia da experiência, uma empresa deixa de oferecer produtos ou serviços e passa a lidar com sensações, heranças culturais ou opções pessoais (PINE II \& GILMORE, 1999). O valor econômico dessa relação não se concentra apenas na conquista ou fidelização do cliente, concentra-se, também, na valorização de um mesmo produto por conta de sua condição especial para determinado cliente e em sua capacidade de eternizar-se.

Todos precisam comprar comida (WOLF, 1999), porém o consumo do entretenimento ativa o desejo e torna a experiência do consumo memorável, atendendo não somente às necessidades básicas. Para tanto, as empresas recorrem aos mais diversos mecanismos para atrair consumidores e aumentar 0 faturamento.

Contudo, as experiências não são exclusivamente sobre entretenimento, uma vez que as empresas se desenvolvem sempre que envolvem os clientes de uma maneira particular e inesquecível (WOLF, 1999). Portanto, o conceito de economia da experiência pode ser incorporado a qualquer empresa que usa mecanismos para envolver os clientes em seus propósitos.

Ressalta-se ainda a diferenciação entre produtos, serviços e experiências. As empresas não precisam atuar somente com experiências, outros produtos e serviços podem continuar sendo vendidos, com 0 intuito de aumentar a lucratividade e reforçar o contexto da experiência.

Em síntese, o entretenimento é concebido como qualquer atividade que ofereça uma experiência prazerosa e satisfatória aos indivíduos, geralmente, no seu tempo-livre, a exemplo do cinema, esportes, parques temáticos, teatro, viagens e outros eventos.

$\mathrm{Na}$ prostituição, atividade caracterizada como a troca de favores sexuais por dinheiro, espera-se que sentimentos, como amor e afeto não estejam presentes. 
Nessa profissão, considerada como "a mais antiga do mundo", o corpo torna-se o principal instrumento de trabalho e o sexo também pode ser pago com favores profissionais, informações, bem materiais e outras remunerações combinadas antes do encontro.

O entretenimento, segundo TRIGO (2013) é uma grande possibilidade nas sociedades pós-industriais e o sexo um dos seus setores mais desenvolvidos, ramificando em muitos desejos, possíveis ou fantasiados.

Considerando o objeto deste estudo, que é a prostituição, a oferta de serviços relacionados à mercantilização do sexo assume um caráter mais segmentado, na medida em que a espetacularização promovida pelo Real Privê eleva esta mercantilização a negócio de luxo, exclusivo, discreto, mediante a adoção de estratégias do mix de comunicação de marketing. A finalidade consiste em atrair seus clientes e tornar o consumo de seus serviços uma experiência memorável.

\section{O MERCADO DO SEXO E A ECONOMIA DA EXPERIÊNCIA}

Destaca-se um ponto observado no campo da pesquisa, ou seja, a atuação da empresa em publicidade local. Anteriormente, o RP estabelecia uma comunicação mais velada, discreta e sofisticada com os clientes da cidade por meio de alguns outdoors em pontos estratégicos, como Aeroporto e saídas da cidade, evidenciando a discrição e luxo que a casa oferecia. A arte apresentava um olho bem maquiado de uma mulher e acima somente o nome do local (Figura 1). Essa era a sua marca registrada.

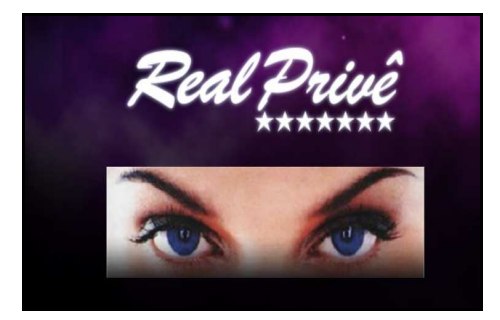

FIGURA 1 - Propaganda da marca Real Privê

Fonte: web site da empresa

Porém, o proprietário explicita que:

"Os empresários desta área não veem suas casas como negócios, isto eu trouxe das multinacionais. Não me importo com a concorrência, eles até impulsionam o meu negócio, quanto mais as pessoas procuram por sexo, mais facilita a divulgação do RP, o que ofereço aqui, nenhuma outra casa oferece, discrição, qualidade, um bom atendimento, sofisticação e as melhores meninas".

Sob essa perspectiva, houve uma mudança significativa dessa comunicação, - RP passa a promover shows com modelos famosas, capas de revistas, miss bumbum, participantes de reality shows e de programas de TV, com o propósito de reforçar o imaginário da população sobre a empresa, o que ela oferece e reforçar a oferta do sexo (Figura 2).

A publicidade projeta uma sensação de gratificação e proteção inconsciente, despertando os desejos. BAUDRILLARD (2000) chama esse efeito de lógica da crença e regressão. As pessoas, como consumidoras, acreditam, mas também se 
projetam diante do discurso publicitário e consideram natural o comportamento de compra.

"Numa sociedade em que praticamente tudo se acha rigorosamente submetido às leis da venda e do lucro, a publicidade é o produto mais democrático, o único que é "ofertado" e ofertado a todos. A publicidade é um jogo de presente e gratificação. Os dois visam transformar em relação pessoal a relação comercial pura". (BAUDRILLARD, 2000).
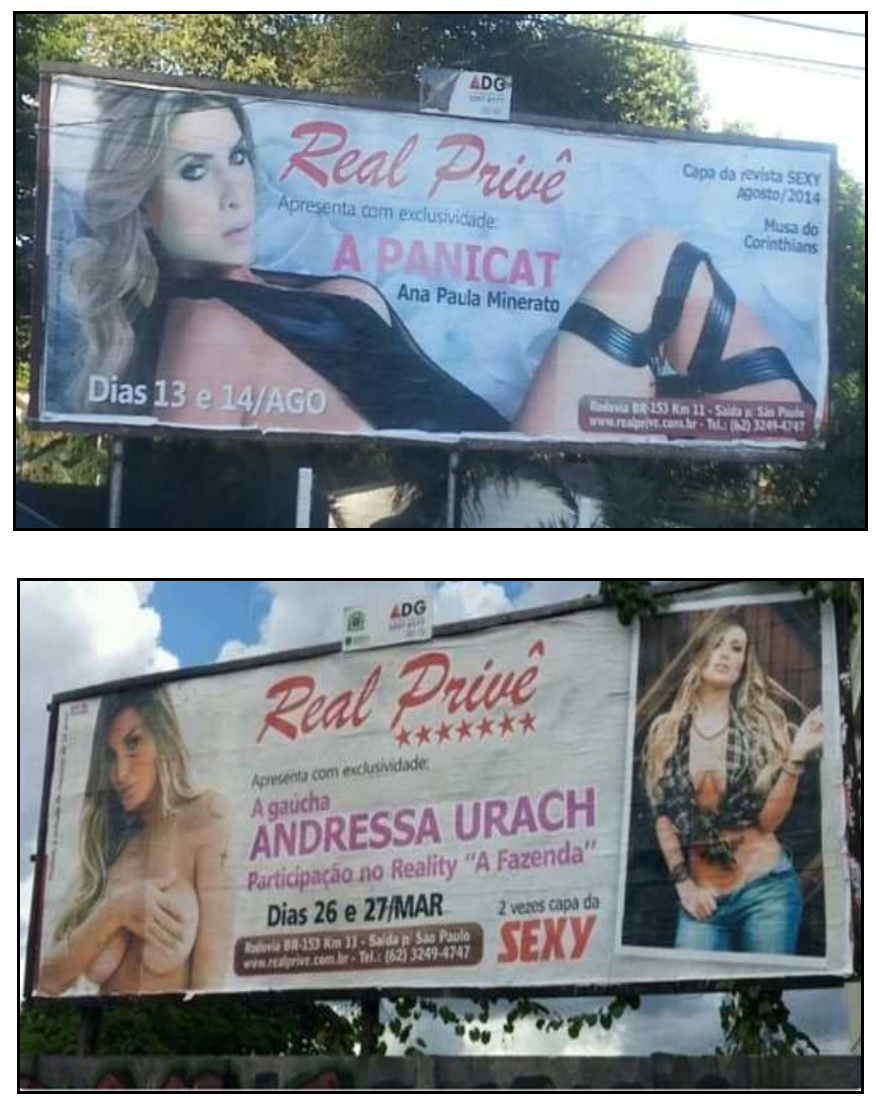

FIGURA 2 - Modelos de outdoors usados pelo Real Privê na divulgação de shows com celebridades Fonte: Acervo dos autores

Todavia, o entrevistado é contundente ao afirmar que a prostituição não é, de forma alguma, a atividade fim do negócio do RP, por se tratar de uma casa de shows, classificada como entretenimento. Se os clientes desejam negociar outros serviços com as "meninas" da casa, o programa ocorre fora do ambiente do RP, ou seja, a empresa não disponibiliza programas, mas sim shows de strip-tease com dançarinas e modelos. Isso não deixa de ser uma forma velada de favorecimento à prostituição e incitação ao sexo.

A própria marca RP, no imaginário popular, já vem carregada de símbolos e significados relacionados à mercantilização do sexo. Propagandas expostas em outdoors, por exemplo, induzem a necessidade de vivenciar experiências propiciadas pelo ambiente da casa de shows de strip-tease. Nesse caso, o consumo 
acontece de acordo com interesses alheios e pré-determinados pelo marketing, responsáveis pela criação da simbologia, dos signos que cada produto/serviço representa (AAKER, 2007).

Na realidade, é a associação do produto ou serviço à emoção a qual faz parte do imaginário coletivo, o que garante o sucesso das marcas bem-sucedidas. Em outras palavras, significa a maneira como as prioridades de compra são escolhidas está presente no inconsciente pessoal em forma de valores e crenças (AAKER, 1996).

$\mathrm{Na}$ opinião do entrevistado, o negócio RP procura criar oportunidades de envolver os clientes por meio de sensações, sendo que quanto maior for o esforço para mantê-los entretidos por meio dos diferentes sentidos, maiores serão as chances das experiências serem apreciadas. Isso porque, todo o empreendimento foi criado para oferecer conforto e sofisticação aos clientes.

Ao avaliar as ferramentas de gestão estratégica aplicada à mercantilização do sexo, percebe-se que, a partir da solidificação da empresa no local e a simbologia que ela já produz na sociedade, surgiram outros negócios próximos ao RP, como: Estância MM, Boate Roma Show, Boate Class. Esta concorrência não afeta as estratégias utilizadas pela casa para atrair clientes, ao contrário, segundo o proprietário, quanto mais há procura por sexo, mais seu negócio é fomentado.

Marketing e a indústria do sexo são parecidos, pois ambos exploram uma angústia do indivíduo (MOUTINHO, 2014). Além disso, os dois sempre buscam formas diferentes de se explorar a mesma matéria-prima, embora a ideia de alinhar o marketing com a prostituição seja bastante realista, mesmo que exista ainda um preconceito da sociedade em interpretar o sexo pago como forma de trabalho. Essa estratégia é adotada pelo RP, como pode ser visto na Figura 3.
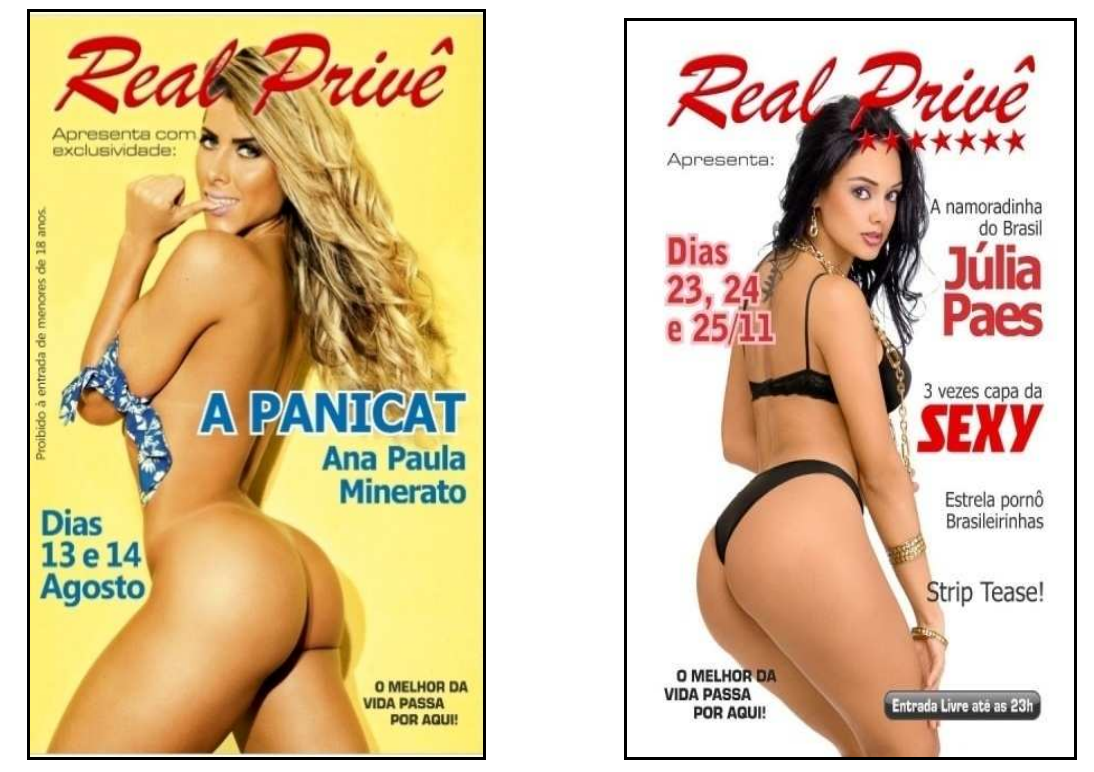

FIGURA 3 - Propaganda de shows veiculados pelo Real Privê Fonte: web site da empresa

As publicidades expostas, em toda a cidade, induzem a necessidade de vivenciar experiências únicas. Em um ambiente seguro, discreto e sofisticado é 
possível ver um show de strip-tease com uma modelo famosa, mas também a possibilidade de comprar sexo com uma garota de programa diferenciada.

Nesse aspecto, a relação emocional gerada no consumo do entretenimento começa mesmo antes de ser consumido. Aqui é gerada uma expectativa do produto/serviço procurado que ultrapassa a satisfação. De acordo com o WOLF (1999), "[...] o ponto fundamental para o sucesso do entretenimento é que o consumidor precisa se ver no produto".

Esta simbologia e signo que o RP desenha e cria, reflete também nas garotas que circulam na casa e oferecem programas. Apesar de não haver nenhum tipo de contrato formal entre a empresa e as garotas de programa, as "meninas" (como todos do estabelecimento chamam as garotas de programa) são selecionadas pelo proprietário antes de ser liberado o seu acesso à casa durante o funcionamento

Em visita ao RP, como observador, percebe-se que as garotas são orientadas a estimular o consumo de bebidas, assim que elas se sentam à mesa com os clientes já chamam o garçom (que já está orientado para esse atendimento), pede uma bebida, geralmente destilados, tudo acontece como se já estivesse roteirizado e ensaiado.

Contempla-se um espetáculo acontecendo em tempo real, tudo para criar um ambiente estimulante e uma experiência sensorial aos clientes. A grande relação com o consumo surge no fato de que apesar de grupos de homens gostarem de comentar que estiveram nesse tipo de estabelecimento, o que consumiram, o que fizeram e com quem saíram, não saem levando produto ou souvenier para relembrar onde estiveram, tudo fica somente na memória.

Segundo TRIGO (2007), "As pessoas possuem um ideal de parceira (o) sexual. Essa idealização é variada e depende dos gostos individuais. Porém, a juventude, a saúde e a estética exercem poderosas atrações." Nesse sentido, todas as justificativas da procura pelo estabelecimento usadas pelos clientes direcionam aspectos como belezas das garotas que dançam e que circulam no ambiente durante seu funcionamento.

Em entrevista com o proprietário houve um relato sobre o público frequentador do RP: "Meu maior e melhor público são as pessoas que estão de passagem por Goiânia, seja a negócios ou a passeio. Esse pessoal vem à procura de sexo e dispostos a gastar dinheiro. O público de Goiânia é composto por pessoas mais jovens, não gastam muito e pegam os contatos das meninas para fecharem os programas sem virem aqui."

As pessoas de passagem citadas pelo proprietário são, na realidade, os turistas que visitam a cidade, mesmo que ele não considere que a cidade seja essencialmente turística. Há uma grande relação do comportamento sexual dos turistas, que por não estarem sendo observados pelas pessoas de seu cotidiano, se sentem de certa forma livres para realizar suas fantasias sexuais (LANZARINI \& TRIGO, 2014). Sobre o público-alvo do Real Privê é possível ter um maior controle

A denominação garota de programa foi aqui adotada para designar as mulheres que trabalham no ramo do sexo, pois como qualquer outra atividade, elas oferecem sua força de trabalho (o corpo) em troca de remuneração.

Após visitas e procura por meios que oportunizassem uma aproximação de forma mais efetiva das garotas de programa que atuam no RP, foi possível conversar com três, especificamente, orientado por um roteiro semiestruturado que fora anteriormente elaborado. 
Nesta entrevista foram levantadas questões, como: faixa etária, tempo de atuação no mercado como garota de programa, relação de contrato com o estabelecimento, rendimento mensal entre outros.

A faixa etária das garotas está entre 18 e 25 anos, estão há mais de um ano se prostituindo, porém a menos de um ano atuando no RP e chegaram até ao estabelecimento por indicação de amigas. Em todos os casos não há uma formalização de contrato entre as garotas e o estabelecimento, portanto nenhum tipo de repasse financeiro à empresa ou algum intermediário.

Foi perguntado se elas seriam pagas pelos shows de strip-tease. Algumas afirmaram que não há pagamento por shows, pois eles são uma estratégia para "atiçar" os clientes e fechar programas, mas uma entrevistada relatou que algumas poucas garotas que são "escolhidas a dedo" pelo proprietário são remuneradas no valor entre $R \$ 1.000,00$ a $R \$ 1.500,00$ por show e mediante a um contrato de gaveta. Em termos de valores totais foi respondido que os ganhos mensais giram em torno de $\mathrm{R} \$ 10.000,00$ a $\mathrm{R} \$ 20.000,00$ mensais, dependendo da quantidade de programas realizados.

A respeito do faturamento e sobre o porquê estarem no Real Privê, todas convergiram na resposta de que o ambiente local proporciona a possibilidade de bons negócios, uma exposição menos evidente e perigosa do que um site ou ficar em pontos na rua. $O$ estabelecimento gera um clima de maior segurança para as garotas. Os valores dos programas giram em torno de $R \$ 400,00$ a $R \$ 500,00$, depende muito do cliente e da negociação que as garotas fazem. Em geral, as garotas recebem em dinheiro e antes de saírem para o motel (elas guardam o dinheiro em suas bolsas e em armários trancados com chave no próprio Real Privê), em um caso a entrevistada relata que já saiu sem cobrar nada do cliente porque gostou do "cara".

Ao serem questionadas sobre diferenciais em relação a outras garotas de programa, elas apontam a beleza e o cuidado com o corpo (físico e estético). Por último foram questionadas a respeito da motivação de escolherem esse ramo, as respostas possuem duas naturezas: econômica e sexual.

Segundo CECCARELLI (2008), a profissional do sexo não existe sem o cliente. Entre eles há um movimento mútuo e complementar de oferta e demanda: é por existirem, de ambos os lados, desejos em busca de satisfação, promessa de satisfazê-los que a prostituição sempre existiu e continuará existindo, mesmo nos lugares em que sua prática seja oficialmente proibida. Todos os elementos presentes na construção do universo erótico da prostituição (local, formas de sedução, promessas, confidências, preço, adereços, vestimentas, fetiches, etc.) se misturam de forma que é impossível saber quem está realizando a fantasia de quem, embora, objetivamente, os papéis estejam bem definidos.

Percebe-se que, apesar de ser uma empresa que utiliza da espetacularização do sexo como atrativo, sofre as mesmas influências de qualquer organização regional, são elas: impostos, ações do poder público, concorrência, mercados. Dessa forma, se considerado o volume de pessoas no estabelecimento e o consumo, mesmo sem dados reais da empresa para comprovação de rentabilidade ou lucro, verifica-se que o negócio é lucrativo mesmo sem intermediação ou recebimento, por parte da RP, de valores oriundos dos programas negociados pelas garotas. Não se pode averiguar nem evidenciar nenhum mecanismo ou ferramenta que tipificasse a exploração da prostituição. 
A espetacularização da oferta do sexo, neste caso apresentado, segmenta o mercado e afeta o espaço que ele atua, pois, os shows com mulheres que estão em destaque na mídia aumentam a quantidade de procura por sexo e cria uma simbologia de "coisa" luxuosa. Esta estratégia configura o diferencial utilizado pelo $\mathrm{RP}$ e permite ao empresário cobrar valores mais altos, tanto para a entrada, quanto para o valor dos produtos vendidos dentro do estabelecimento.

A discussão sobre este assunto ou sobre este tipo de empresa sempre permeia o campo moral, além disso, os mecanismos de gestão utilizados pela empresa Real Privê para divulgação de seu negócio incomodou a cidade de Goiânia, fazendo com que parte da sociedade organizada se mobilizasse, como também pressionasse o poder público, a fim de modificar a Legislação municipal, com a promulgação da Lei ํo 9.506, de 10 de dezembro de 2014, que proibiu a veiculação de propaganda com fins eróticos e outras atividades semelhantes.

\section{CONCLUSÃO}

Ao investigar se existe relação entre as estratégias do mundo empresarial e a exploração da prostituição como negócio de luxo, retrata-se sobre a evolução histórica da oferta do sexo como mercadoria, colocando em evidência as ferramentas de gestão para agregar valor e divulgar o negócio de uma casa de shows em Goiânia.

Com um enfoque de gestão estratégica e a partir de referencial bibliográfico, a análise se pauta na segmentação de mercado e posicionamento competitivo utilizados pelo Real Privê, caracterizado como casa de espetáculos erotizados, fundamentando-se no entendimento de que, ao inserir a prostituição no mundo corporativo, é importante que as empresas desse mercado estejam preparadas estrategicamente para vencer a concorrência.

Com a mercantilização do sexo de luxo não é diferente, uma vez que a busca por experiências de consumo, fenômeno recorrente diante da Economia da Experiência vivenciada pelo homem, possibilita às empresas do ramo construir ambientes de serviços, nos quais as sensações provocadas nos clientes possam atuar como elementos diferenciais, em relação à concorrência.

O RP é hoje uma referência no mercado de entretenimento adulto, pois oferece muito conforto, sofisticação, requinte e discrição aos seus clientes. Não por acaso, a casa conquista o seu espaço, constrói uma marca forte, mas também reconhecida nacionalmente. De fato, o posicionamento da marca consiste em uma importante estratégia utilizada para criar a posição desejada na mente dos clientes, criando assim uma identidade importantíssima para que seja moldado o serviço.

Dessa forma, as estratégias utilizadas para atrair os clientes do RP estão sustentadas no conhecimento do cliente e do mercado. Isso facilita a definição daquelas que despertam o interesse do cliente e oferece o que ele espera. Mais do que 0 produto, nesse meio, é fundamental oferecer a experiência que o cliente deseja. O valor agregado é a principal diferença dos produtos que geram experiências. Interagindo com os clientes, fica possível gerar essas experiências positivas.

O proprietário descarta a ideia de que seu empreendimento seja um negócio de prostituição e o enxerga como entretenimento. Analisando por esse aspecto, pode-se concluir que a segmentação do sexo de luxo faz a prostituição assumir um 
caráter mais aceitável entre a sociedade, embora haja restrições do mercado em considerá-la como atividade relacionada ao sexo, enquanto que, por parte dos clientes, o mercado do sexo é visto com entretenimento e não como prostituição.

Ressalta-se também que, por parte do RP, o espetáculo camufla, como também dificulta (de certa forma) a tipificação da exploração sexual. Porém, é evidente que todo o negócio e sua cadeia produtiva gira em torno do sexo, pois sem esse argumento, ele poderia não ser viável. Por parte das garotas que oferecem e realizam programas, há evidências de que o estabelecimento e a produção do espetáculo camuflam sua atividade, possibilitando uma vida social em um contexto em que não são reconhecidas como prostitutas.

Ressalta-se que este estudo não teve a pretensão de apresentar uma versão determinante sobre o tema. Tem-se a convicção de que os resultados apresentados na pesquisa exigem continuidade.

\section{REFERÊNCIAS}

AAKER, D. A. Administração estratégia de mercado. 7. ed. Porto Alegre: Bookman, 2007.

AAKER, D. A. Criando e administrando marcas de sucesso. São Paulo: Futura, 1996.

ARAÚJO, C. M. B.; LOUREIRO, C. M. C. C. Tourism \& Management Studies, v. 10, Número Especial, p. 103-110, 2014.

BAUDRILLARD, Jean. A sociedade de consumo. Rio de Janeiro: Elfos, 1995.

BRASIL. Lei no 12.015, de 7 de agosto de 2009. Altera o Título VI da Parte Especial do Decreto-Lei ${ }^{\circ} 2.848$, de 7 de dezembro de 1940 - Código Penal, e o art. $1^{\circ}$ da Lei $\mathrm{n}^{\circ}$ 8.072, de 25 de julho de 1990, que dispõe sobre os crimes hediondos, nos termos do inciso XLIII do art. $5^{\circ}$ da Constituição Federal e revoga a Lei $n^{\circ} 2.252$, de $1^{\circ}$ de julho de 1954, que trata de corrupção de menores. Presidência da República, Casa Civil, Subchefia para Assuntos Jurídicos. Disponível em:: <http://www.planalto.gov.br/ccivil_03/_ato2007-2010/2009/lei/l12015.htm>. Acesso em: 19 set. 2014.

CASTARÈDE, J. O luxo: os segredos dos produtos mais desejados do mundo. Tradução Mário Vilela. São Paulo: Barcarolla, 2005.

CECCARELLI, P. R. Prostituição-Corpo como Mercadoria. In: Mente \& Cérebro sexo, v.4, dez. 2008. Disponível em: <ceccarelli.psc.br/pt/?page_id=157> Acesso em 11 jan. 2015.

CERTO, S. C.; PETER, P. J. Administração estratégica: planejamento implantação da estratégia. 3. ed. São Paulo: Makron Books, 2010. 
CUNHA, C.; RIBEIRO, N. De casas personalizadas a exibição na web, mercado do sexo fatura alto. Artigo, 2014. Disponível em: <impressaodigital126.com.br/?p=20019 . Acesso em 23 jun. 2015.

DANZIGER, P. Let them eat cake: marketing luxury to the massesas well as the classes. Chicago: Kaplan Publishing, 2005.

HENDERSON, B. D. As origens da estratégia. In: MONTGOMERY, C.; PORTER, M. Estratégia: a busca da vantagem competitiva. 3. ed. Rio de Janeiro: Campus, 1998.

HOOLEY, G.; PIERCY, N. F.; NICOULAUD, B. Estratégia de marketing e posicionamento competitivo. 4. ed. São Paulo: Pearson Prentice Hall, 2011.

KOTLER, P. Administração de marketing: análise, planejamento, implantação e controle. 5. ed. São Paulo: Atlas, 2009.

IBGE. Instituto Brasileiro de Geografia e Estatística. Goiânia. População estimada 2015. Disponível em: <cidades.ibge.gov.br/xtras/perfil.php?codmun=520870>. Acesso em 20 mar. 2015.

KOTLER, P.; ARMSTRONG, G. Princípios de Marketing. 12. ed. Janeiro: PrenticeHall, 2010.

LANZARINI, R.; TRIGO, L. G. G. Lazer sexual masculino no Brasil. Turismo e Desenvolvimento, v. 2, n. 21/22, p. 59-67, 2014.

LEAL, M. L. Crianças e adolescentes no mercado do sexo - fetichismo e precarização. Criança e adolescente: direitos, sexualidades e reprodução. São Paulo: ABMP, 2010.

LIPOVETSKY, G. O império do efêmero: a moda e seu destino nas sociedades modernas. Tradução Maria Lucia Machado. São Paulo: Companhia das Letras, 2009.

MINTZBERG, H. Patterns in strategy formation. Management Science, v. 29, n. 9, p. $934-48,1978$.

MINTZBERG, H. The Design School: reconsidering the basic premises of strategic management. Strategic Management Journal, v. 11, n. 3, p. 171-195, 1990.

MOUTINHO, F. A indústria do sexo e o marketing. Disponível em: $<$ https://fabiomoutinho.wordpress.com/2011/.../a-industria-do-sexo-e-o-marketing/>. Acesso em: 14 jun. 2015.

PINE II, J. B.; GILMORE, J. H. Welcome to the experience economy. Harvard Business Review, v.76, n. 4, p. 97-105, 1998.

RODRIGUES, M. T. A prostituição no Brasil contemporâneo: um trabalho como outro qualquer? Revista Kutal, v. 12, n. 1, p. 68-76, 2009. 
RUSSO, G. No Labirinto da prostituição: o dinheiro e seus aspectos simbólicos. Caderno CRH, v. 20, n. 51, p. 497-514, 2007.

STEARNS, P. N. História da Sexualidade. Tradução Renato Marques. São Paulo: Contexto, 2010.

SILVERSTEIN, M.J.; FISKE, N.; BUTMAN, J. Trading Up: The New American Luxury. New York: Portfolio, 2005.

SWAIN, T. N. Banalizar e naturalizar a prostituição: violência social e histórica. Unimontes Científica, v. 6, n. 2, p. 24-29, 2004.

RODRIGUES, M. T. A prostituição no Brasil contemporâneo: um trabalho como outro qualquer?. Rev. katálysis [online], v.12, n.1, p. 68-76, 2008. Disponível em: < http://www.scielo.br/scielo.php?script=sci_arttext\&pid=S1414-49802009000100009>. Acesso em 17 jun. 2015.

TRIGO, L. G. G. Entretenimento: uma crítica aberta. São Paulo: Senac, 2003.

TRIGO, L. G. G. Desejo e entretenimento: Imaginário homoerótico ocidental - da sublimação ficcional ao produto descartável. Intercom - Sociedade Brasileira de Estudos Interdisciplinares da Comunicação. XXX Congresso Brasileiro de Ciências da Comunicação - Santos - 29 de agosto a 2 de setembro de 2007.

TRIGO, L. G. G. A viagem: caminho e experiência. São Paulo: Aleph, 2013.

WEITZER, R. Sex for Sale: Prostitution, Pornography and the Sex Industry. 2. ed. New York, USA: Taylor \& Francis, 2010.

WOLF, M. J. The Entertainment Economy. USA: Penguin Books, 1999. 